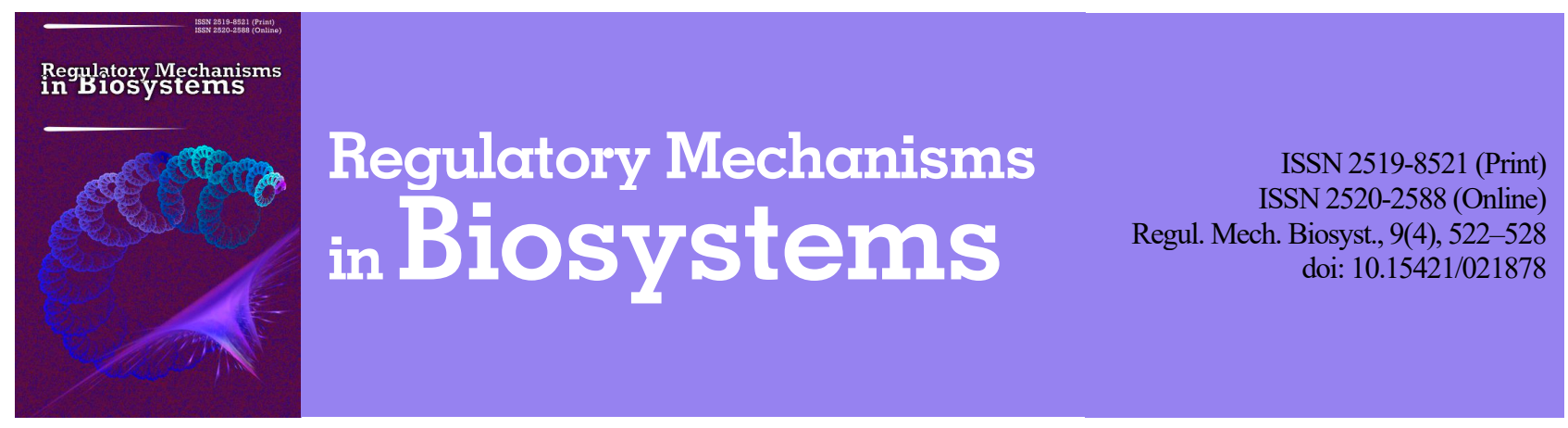

\title{
Peculiarities of PED virus pathogenesis in neonatal non-immune piglets on Ukraine farms
}

\author{
D. N. Masiuk, , V. S. Nedzvetsky ${ }^{*, * *}$, A. I. Sosnztskyi , A. V. Kokariev", A. I. Zavhorodnii ${ }^{* * *}$ \\ ${ }^{*}$ Dnipro State Agrarian and Economic University, Dnipro, Ukraine \\ ${ }^{* * *}$ Bingöl University, Bingöl, Turkey \\ ${ }^{* * *}$ Institute of Experimental and Clinical Veterinary Medicine, Kharkiv, Ukraine
}

\author{
Article info \\ Received 01.10.2018 \\ Received in revised form \\ 11.11.2018 \\ Accepted 13.11.2018
}

Dnipro State Agrarian and Economic University Sergiy Efremov st., 25, Dnipro, 49000, Ukraine. Tel.: +38-056-713-51-74.

Bingöl University,

Selahaddin-I Eyyubi Mah, Bingöl, 12000, Turkey. Tel.: +90-426-216-00-12. E-mail:

nedzvetskyvictor@ukr.net

Institute of Experimental and Clinical Veterinary Medicine Pushkinska st., 83, Kharkiv, 61023, Ukraine.

Tel.: +38-057-704-20-53

\begin{abstract}
Masiuk, D. N., Nedzvetsky, V. S., Sosnztskyi, A. I., Kokariev, A. V., \& Zavhorodnii, A. I. (2018). Peculiarities of PED virus pathogenesis in neonatal non-immune piglets on Ukraine farms. Regulatory Mechanisms in Biosystems, 9(4), 522-528. doi:10.15421/021878
\end{abstract}

The article presents the results of study of the immune and tissue features of pathogenesis of PED virus in neonatal piglets in Ukraine. Clinical and epizootological analysis was performed in three separate agricultural enterprises with adverse epidemiological situation with PED virus. Blood samples and fragments of the small intestine of PEDv infected piglets were used to study the characteristics of the pathogenesis of PED virus. It has been determined that the pathogenesis of super-acute infection by the PED virus in 1-7 day old non-immune piglets proceeds according to the classic type of infectious process with a relay transmission of the pathogen. Moreover, diarrhea syndrome has induced the development of irreversible and lethal pathophysiological lesions by replication the PED virus in enterocytes of infected piglets. Pathogenetic changes observed in PEDv infected piglets were combined with the following components: acute inflammatory-necrotic process in the tissue of the intestine, destruction and desquamation of the epithelium of the small intestine. The infection process on day 3-5 of manifestation of clinical signs of PED virus is accompanied with an increase in the number of erythrocytes, leukocytes and monocytes, hemoglobin, hematocrit level and aminotransferase activity. In addition, PED virus infection induced an increase in IgM levels and the number of phagocytizing leukocytes with increased aggressiveness and digestive power. The duration of the release of PED virus with feces is $26-37$ days after cessation of watery diarrhea. The concentration of PEDv in the feces of convalescent piglets ranged from 120 to 1700 equivalent genome in $1 \mathrm{~g}$ of tissue. Parasite coenotic associations of the microbiocenosis of the digestive tract of PED virus infected piglets did not have time to form into stable epitopes. There was a constant quantitative prevalence of transient microbiota and a decrease in the share of probiotic microorganisms. The intestinal microflora consists of random transient microbiota of the environment with pathogenic properties. The results presented show evidence that molecular and cell-mediated immunological events in non-immune piglets have the initial stage of the specific progress of immune response against PEDv.

Keywords: PEDv; pathogenesis; piglets; morphological and biochemical indicators of blood; cell-mediated immunity; humoral immunity; intestinal microbiocenosis

\section{Introduction}

Porcine epidemic diarrhea virus (PED) is an emergent, highly contagious viral disease of pigs of all ages with the progress of a lethal diarrhea syndrome in non-immune piglets, who suffer almost $100 \%$ mortality in the early postnatal period (1-7 days), with a primary outbreak of infection.

Synonyms: Piglets epidemic diarrhea - PED; Porcine Epidemic Diarrhoea - PED; Transmissible gastroenteritis of swine like disease; Vomiting and wasting disease in piglets (English); Erbrechen und Kummern bein Sagferkel (German) (Ouyang et al., 2015).

The causative agent is Porcine Epidemic Diarrhea virus (PEDv). Taxonomy: genus - Alphacoronaevirus, family - Coronaeviridae, order Nidovirales. There are two subtypes of the virus: PEDv type 1 - causes diarrhea syndrome in mature animals and suckling piglets, except for prenursery pigs; PEDv type 2 - also affects prenursery pigs. The virus is antigenically homogeneous, according to the results of sequencing, there are two genetic items - North American and Chinese, which are characterized by a high degree of genome homology (Kocherhans et al., 2001; Jung et al., 2015; Miller et al., 2016). According to the results of the global monitoring observations presented OIE, porcine epidemic diarrhea is recognized as one of the most dangerous and emergent virus infections of neonatal piglets. The emergence of the PED virus is comparable to African swine fever, classical swine fever, swine respiratoryreproductive syndrome and circovirosis. An important and key biological property of PEDv is an extremely high capacity for spontaneous mutation in field variants of the virus, which determines the significant genetic heterogeneity of epizootic isolates and their virulence variability. The mutant PEDv clones express the modified antigens, which allow them to effectively avoid vaccine-stimulated immune control. The lack of immune control in a short time leads to the progress of infection in farms (local populations), and high pathogenicity for neonatal nonimmune piglets leads to significant economic losses (Pillatzki et al., 2015; Thomas et al., 2015; Chen et al., 2016).

The main path of PEDv infection in sensitive animals is the faecaloral transmission. However, there are many indirect possibilities of infection through contamination with the virus of environment objects, such as clothing and footwear of personnel, vehicles, feed, food, pig factory waste, and also such infection vectors as insects and rodents (Masiuk et al., 2018). Poor-quality disinfection and long-term preservation of the virus in the external environment, especially during the cold season, cause a serious epizootic risk (Lowe et al., 2014; Lin et al., 2015; 
Crawford et al., 2015). The lack of effective antiviral agents that fundamentally break the epizootic chain of PED infection in a wide range of genetic variants of field virus strains determines the complexity of antiinfectious preventive measures. Moreover, despite the use of modern laboratory diagnostic systems, the variability of mutant strains is a significant cause of the late detection of the PED causative agent. Destruction of infected individuals, carrying out disinfection measures, replacement of livestock can still leave a chance of the infection recurring when compliance with the regulatory requirements is incompletely realized (Lee, 2015).

The main symptom of PEDv pathogenesis is watery diarrhea. In typical cases, all symptoms of diarrhea develop. With a disease outbreak in a sensitive population, morbidity and mortality can vary considerably. Infected piglets which are 7-10 days of age usually die within 3 to 4 days as a consequence of both dehydration and intoxication in the course of the PED virus infection. The average mortality rate is $50 \%$, but it can reach $90-100 \%$. In fattening farms, in most cases, there is a significant variability of clinical signs during an acute PEDv outbreak. Disease symptoms observed in week-old piglets are manifested by depressed behaviour, a lack of appetite, secretion of watery feces without any signs of blood. Recovery, as a rule, occurs in 7-10 days, mortality is $1-3 \%$. However, the range of mortality can increase as a result of other environmental factors, especially the stress induced by uncomfortable caging and technological disturbances. The PED virus shedding to pigs is usually slower than transmissible gastroenteritis on breeding farms and takes from 4 to 5 weeks after the pathogen enters the population of sensitive animals (Stevenson et al., 2013; Lowe et al., 2014). The aim - to study the specific immune and tissue features of the PED virus pathogenesis in neonatal piglets on Ukrainian farms.

\section{Materials and methods}

The work was carried out in the laboratory of the Research Center for Biosafety and Environmental Control of Resources of the AgroIn dustrial Complex of the Dnipro State Agrarian and Economic University. Clinical and epizootological analysis was performed in three differrent agricultural enterprises with adverse epidemiological situation with the PED virus using routine methods of collecting and processing data describing the symptom complex of the disease, taking into account clinical signs, age, distribution and duration of infectious diseases, the number of dead and diseased animals, as well as identified pathological changes.

As the main criteria for the creation of the algorithm, data on anamnesis, laboratory tests of virus-containing samples from animals, immunobiological studies of hematological and immune indicators of pigs during the development of an infectious process were used. The groups of piglets with the most characteristic clinical signs were selected on every monitored farm.

Serological diagnostics of PEDv was performed by ELISA using the BioTek EL ${ }^{x} 800$ photoelectric immunoassay analyzer (USA) and the ID Screen ${ }^{\circledR}$ PEDV indirect test system (IDvet, France) according to the manufacturer's instructions. The samples of serum are considered to be $\mathrm{PEDv}$ positive when the $\mathrm{S} / \mathrm{P}$ value of the sample is higher than $0.4 \mathrm{U}$, at a dilution of $1: 10$.

Reverse transcription of RNA of the PED virus, and replication of cDNA was performed using a set of reagents "Bio-T kit $R P E D V$ all TGEV»" ("Biosellal", France) in a CFX 96 Real-Time System thermocycler ("Bio Rad", USA).

Bacteriological examination of the contents of the gastrointestinal tract of the examined piglets included an indication and identification of microorganisms of different taxonomic status. Simple and enriched nutrient mediums were used to isolate aerobic bacteria, namely: plain broth and plain agar in the native form with the addition of $10 \%$ serum, as well as in the cerebral broth, medium R. Hottinger, Endo agar, XLD agar. Analysis of anaerobic microorganisms was accomplished by seeding material into the Kitt-Tarozzi medium and on agar containing 5\% blood.

The morpho-tinctorial and biochemical properties of field crops were studied by routine methods. The pathogenicity of the identified daily cultures of microorganisms was determined in a biological assay performed using white mice. A broth culture of the studied microorganism in a volume of $0.3 \mathrm{~cm}^{3}$ was injected subcutaneously in 5 white mice with weight of 18-20 g. The amount of erythrocytes and leukocytes, hemoglobin and hematocrit level were determined in the blood using the PCE-90 VET automatic hematology analyzer (HTI, USA).

The ratio of various forms of leukocytes was determined with microscopy in blood samples stained by Romanowsky-Giemsa via counting 200 cells.

Biochemical studies of blood serum were performed using an automatic Miura 200 biochemical analyzer (ISE Srl, Italy) and the corresponding reagent kits manufactured by High Technology (USA).

The immune status and indicators of nonspecific resistance were studied by comparative analyses in the samples of both infected and intact piglets.

Bactericidal activity of blood serum was determined by the method of Michel \& Treffers (1956) in modification of Sarukhanov et al. (2007). Lysozyme activity in serum was determined in accordance to Khrabustovskyi et al. (2002). Phagocytic activity of leukocytes (PAL), phagocytic number (PP) and phagocytic index (PI) were determined in stabilized EDTA blood with a Staphylococcus aureus culture by the method described by Kondrakhin et al. (1985). The content of immunoglobulin classes $\mathrm{A}, \mathrm{M}$ and $\mathrm{G}$ in serum was determined by radial immune-diffusion by Mancini et al. (1965).

Variation and statistical processing of the obtained results was performed using the Statistica 6.0 specialized software (StatSoft Inc., USA). The significance of differences was assessed after verifying the experimental data obtained for the normal distribution using Student t-test or its non-parametric counterpart - the Wilcoxon test. Selective parameters presented in the work have the following designations: $\mathrm{x}$ is the sample average, SE is the standard error of the average value.

\section{Results}

The results of the analysis of data obtained from monitoring on the epizootic situation of the presence of the PED virus in the central and south-eastern regions of Ukraine over the past two years showed PEDv presence in $23 \%$ of monitored farms. The PED virus has been identified in three typical pig farms, with an intensive technology for keeping animals and an unsatisfactory level of biosafety. Based on the clinical and epizootological analysis of the occurrence and development of infectious pathology in sensitive animals in previously flourishing farms, the most generalized algorithm for the functioning of an interpopulation parasitic system consisting of a sensitive pig head and a field virus has been created. A complete clinical and epizootological study of infectious pathogenesis conducted in samples of blood and intestinal tissues showed that in all farms the source of PEDv infection remained uncertain. In spite of this unassignable cause of infection, the epizootic process was developed with common features, similar on all the studied considered farms.

The results of the clinical and epizootological monitoring of the infectious process showed that the clinical symptoms characteristic of the PED virus initially manifest themselves on a massive scale in neonatal piglets in a large farrow from conditionally healthy individuals which were previously infected by PEDv pigs. The presence of the virus was confirmed by retrospective indication of IgG to PEDv capsid antigens by ELISA. In $52-68 \%$ of blood serum samples from $10 \%$ of the reproductive herd at a dilution of $1: 200$, antibodies were determined in diagnostic titers.

The results of the analysis of the identified PED infection showed enzootic coverage of susceptible populations, in which the primary outbreak occurred suddenly. Moreover, total infection has is a specific feature towards epizootic events in the farms of Ukraine. At the same time, all the newborn piglets, which were obtained in a large farrow of the recovered pigs that were previously infected with PEDv, fell ill with the typical PED symptom complex. Watery diarrhea in most piglets was detected during the first days after birth, especially from 12 to 18 hours of life. Approximately $25-30 \%$ of the animals developed diarrhea in 2-3 days and only a small number of piglets, no more than $8-10 \%$, developed symptoms of the PED virus in 5-6 days. The diarrhea observed in our study was accompanied with vomiting, some piglets had persistent and very painful vomiting. The feces are liquefied and turned into a colourless or greenish-yellow watery mass, sometimes 
whitish or bright yellow, but without any admixture of blood. Moreover, diarrhea was persistent and quickly led to dehydration. In the course of PED infection, the animals lost weight, their ribs, spine, hook bone began to show, facial bones began protrude. In the terminal stage, the animals passed with a pathological form of exhaustion with a clearly expressed general weakness, apathy, severe depression, up to a reduction and loss of pain reflexes. Muscle turgor was detected as decreased, "stilted gait" and clumsiness of movements appeared, the skin became wrinkled, inelastic, inactive, dry, rough (Fig. 1). Diarrheal syndrome in piglets infected with PEDv on the 10-14 days of life proceeded much more lightly with relatively low lethal outcome, mortality accounting for up to $10-15 \%$ of the cases. Most of the piglets with diarrhea recovered as time went by. Post-infectious asthenia lasted 2-4 weeks and finished with almost complete reparation of impaired physiological functions and restoration of fattening conditions.

Molecular genetic methods RT-PCR were used for the diagnosis of PED. In samples of feces of diseased animals $(n=29)$, PEDv RNA was identified at a concentration of $3.02 \times 10^{7} \pm 9.45 \times 10^{6}$ equivalent genes in $1 \mathrm{~g}$ of the biomaterial. The quantitative characteristics of the genomic material of PEDv are shown in Figure 2.

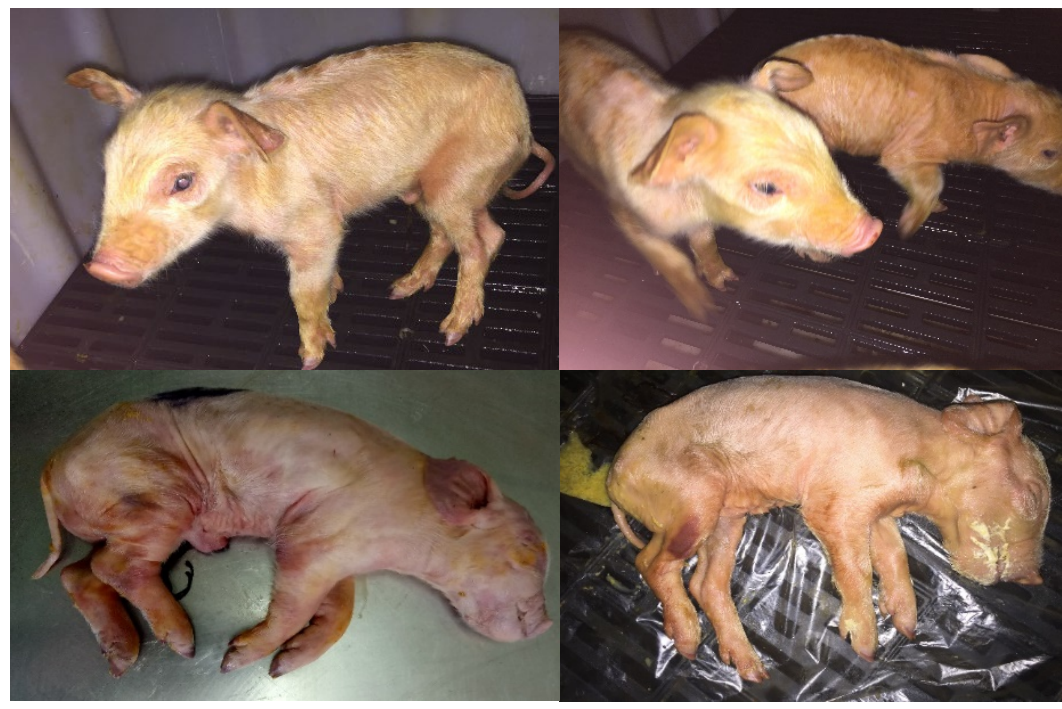

Fig. 1. The clinical signs and postmortem changes in piglets which died from PEDv during the first week of life

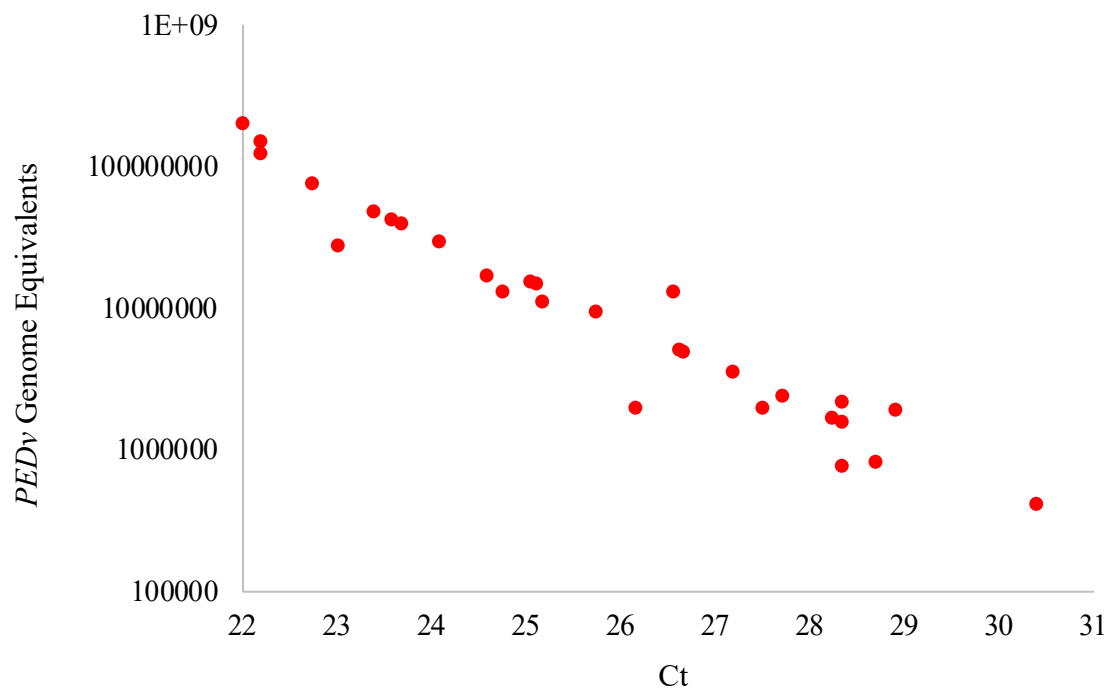

Fig. 2. PEDv cDNA Amplification Products Detection Graph

General depression quickly intensified, piglets noticeably weakened, the appetite was absent, toxic effects, metabolic acidosis and alimentary asthenia increased. The animals were completely passive, exhausted and were constantly lying on their side, showed no muscular activity, reacted poorly to external stimuli and general suppression of vitality was aggravated. After 3 to 6 days of the diarrhea syndrome, against the background of hypothermia, progressive pathological exhaustion and an increase in intoxication with symptoms of deep depression, and stupor, the piglets died in a comatose state from the paralysis of the cardiovascular center. Before death, the mild tonic clonic movements and frothy discharge from the oral cavity were observed.

The mortality among the neonatal piglets in the primary outbreak of PED virus, of individuals in which watery diarrhea was identified in the first postnatal 72 hours, was identified as $100 \%$. Only some of all piglets infected with the PED virus on the 4-5th day, and even fewer on the 6-7th day of life, died after the severe form of diarrhea syndrome, a small number up to $15-20 \%$ of the diseased piglets survived for a long period of time and became convalescents - virus extractors.

Monitoring of 12 convalescent animals isolated from the common herd showed decreasing dynamics in the number of PEDv feces from every individual. Fecal samples were examined daily for the presence of PEDv in RT-PCR until a negative result was obtained. The intense isolation of the virus detected during the first 6-9 days after the cessation of the active phase of watery diarrhoea and was $1700 \pm 80$ of genome equivalents in $1 \mathrm{~g}$ of biomaterial, when $\mathrm{P}<0.01$. In the course of the next two weeks, there was a lytic drop in the amount of virus secreted to relatively small quantities and amounted in 21-25 days to $12 \pm 6$ of equivalent genomes in $1 \mathrm{~g}$ of the biomaterial at $\mathrm{P} \leq 0.01$. After the next 12 days, the virus release ceased for all convalescents. The first case of the virus excretion closure was registered at 26 days and the last - at 
37 days. Within a month, after the last case of registration of PEDv genetic material in the feces of convalescents, weekly control tests were performed to determine whether the pathogen was released into the external environment, but all the samples showed a negative result on the presence of PEDv genetic material in the feces.

The serous membranes of the internal organs were transparent, fat depots of the internal organs were depleted. The spleen was elastic, not enlarged, the borders were sharp, bright red. The brain membranes were edematous, anemic, the brain tissues were pale with collapsed vessels, the consistency of brain tissue was dense.

The results of the analysis of tissue samples showed that the lesions were localized in the gastrointestinal tract, where signs of gastroenterocolitis were pronounced, with desquamation of the secretory epithelium of the small intestine. Mesenteric lymph nodes were dense, deep red on the incision. The disturbances of the small intestine walls were determined with histology analysis. The destruction of the intestine was manifested by significant thinning and catarrhal hemorrhagic inflammation, which is developed in the damaged areas. Histology analysis of the affected areas of the small intestine showed acute catarrhal hemorrhagic inflammation of the mucous membrane which associated with the areas of degenerative changes and local necrotic foci (Fig. 3).

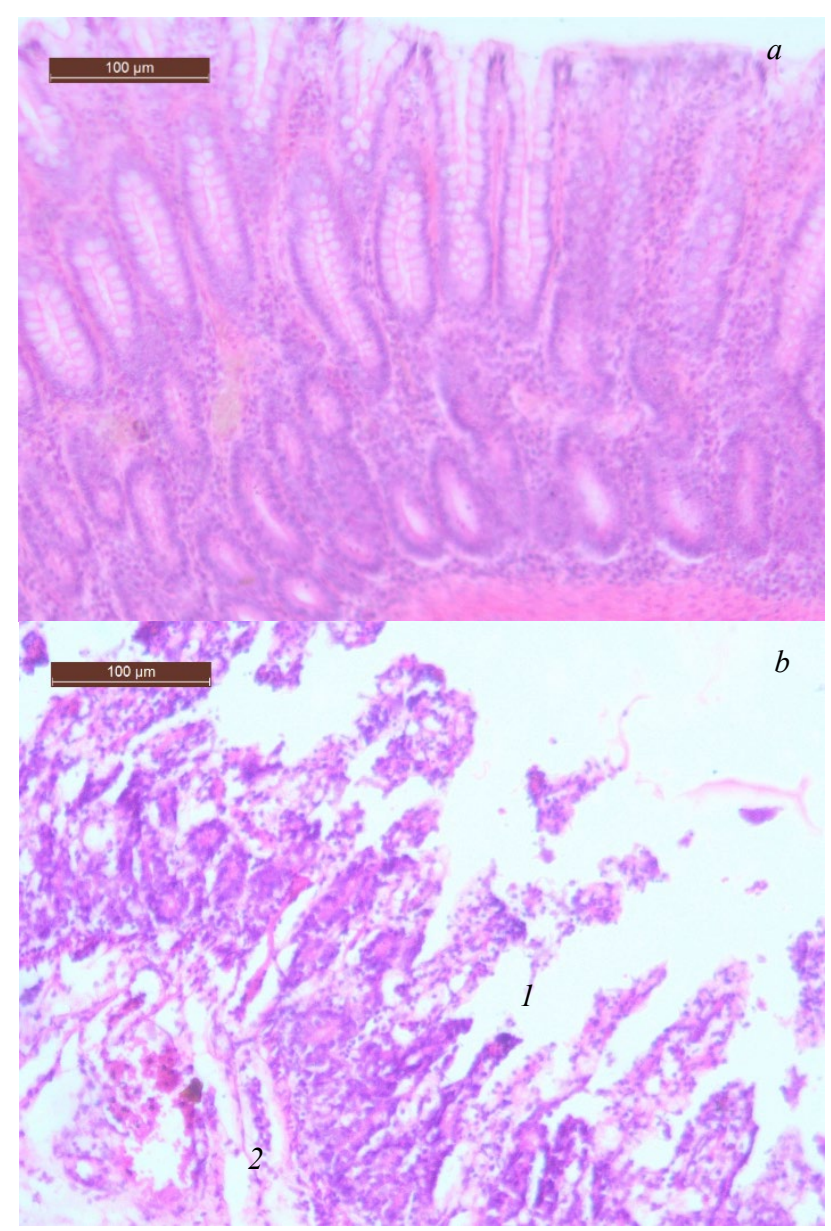

Fig. 3. The results of histology staining of the small intestine of clinically healthy piglets $(a)$ and those infected with PEDv $(b)$ :

hematoxylin-eosin staining; 1 - desquamation of small intestinal epithelial cells, 2 - swelling of the submucosa

Both edema and atrophy of the intestinal villi due to enterocyte desquamation were detected in the mucous membrane. In regional lymph nodes, significant catarrhal-hemorrhagic inflammation, edema of the blood vessels of the follicles, swelling of the capsule and trabecules were observed. In the trabecular lymph nodes, accumulations of a large number of eosinophils were detected.

The analysis of hematological parameters in blood samples of all selected groups revealed pronounced signs of pathogenetic disorders in 16-18 day old piglets, which began to manifest 3-5 days after the ap- pearance of clinical signs of PED virus. The presented results of the analysis of hematological blood parameters in piglets infected with PEDv indicate the increase of relative leukocytosis with absolute monocytosis, against the background of hypovolemic polycythemia (Table 1).

Based on the obtained results, it was determined that in the blood of piglets infected with PEDv there was a significant increase in the number of erythrocytes by $34.1 \%(\mathrm{P}<0.05)$, hemoglobin content by $25.5 \%(\mathrm{P}<0.05)$ and the level of hematocrit index at $61.3 \%(\mathrm{P}<0.05)$ in comparison with healthy animals. There was also a significant increase in the erythrocyte sedimentation rate in the average of 5.93 times $(\mathrm{P}<$ 0.01 ) in comparison with clinically healthy piglets. The results indicate a moderate increase in the inflammatory process.

Table 1

Hematological values of the piglets' blood $(x \pm S E)$

\begin{tabular}{|c|c|c|c|c|}
\hline Blood values & $\begin{array}{c}\text { Control } \\
\text { (clinically } \\
\text { healthy, intact } \\
\text { animals, } \\
\text { n=6) }\end{array}$ & $\begin{array}{c}\text { Piglets with } \\
\text { diarrhoeal } \\
\text { syndrome from } \\
\text { the farm No } 1 \\
(\mathrm{n}=28)\end{array}$ & $\begin{array}{c}\text { Piglets with } \\
\text { diarrhoeal } \\
\text { syndrome from } \\
\text { the farm No } 2 \\
(\mathrm{n}=34)\end{array}$ & $\begin{array}{c}\text { Piglets with } \\
\text { diarrhoeal } \\
\text { syndrome } \\
\text { from the farm } \\
\text { No 3 }(n=32)\end{array}$ \\
\hline Hemoglobin, $\mathrm{g} / \mathrm{dm}^{3}$ & $95.0 \pm 3.8$ & $110.1 \pm 4.3^{*}$ & $128.2 \pm 8.2^{*}$ & $119.4 \pm 7.5^{*}$ \\
\hline $\mathrm{ESR}, \mathrm{mm} / \mathrm{h}$ & $8.2 \pm 0.5$ & $38.4 \pm 2.4^{*}$ & $59.6 \pm 3.3^{*}$ & $47.8 \pm 2.3^{*}$ \\
\hline $\begin{array}{l}\text { Red blood cells, } \\
\mathrm{T} / \mathrm{dm}^{3}\end{array}$ & $5.62 \pm 0.14$ & $7.27 \pm 0.63^{*}$ & $8.19 \pm 0.52^{*}$ & $7.14 \pm 0.71 *$ \\
\hline $\begin{array}{l}\text { Hematocrit, } \% \\
\text { Leukocytes, } \mathrm{g} / \mathrm{dm}^{3}\end{array}$ & $\begin{array}{c}37.1 \pm 1.9 \\
8.20 \pm 0.66\end{array}$ & $\begin{array}{c}56.3 \pm 3.2^{*} \\
15.40 \pm 1.56^{*}\end{array}$ & $\begin{array}{c}64.3 \pm 4.2^{*} \\
18.60 \pm 2.84^{*}\end{array}$ & $\begin{array}{c}58.9 \pm 3.7^{*} \\
14.60 \pm 2.44^{*}\end{array}$ \\
\hline \multicolumn{5}{|c|}{ WBC differential, \% } \\
\hline Basophils & 0 & 0 & 0 & 0 \\
\hline Eosinophils & $1.2 \pm 0.3$ & $1.7 \pm 0.2$ & $1.1 \pm 0.2$ & $0.9 \pm 0.2$ \\
\hline Stab neutrophils & $1.2 \pm 0.3$ & $2.4 \pm 0.4$ & $2.6 \pm 0.2$ & $3.5 \pm 0.3$ \\
\hline $\begin{array}{l}\text { Segmentonuclear } \\
\text { neutrophils }\end{array}$ & $45.8 \pm 3.7$ & $43.8 \pm 4.6$ & $39.3 \pm 3.9$ & $43.3 \pm 3.8$ \\
\hline Lymphocytes & $50.2 \pm 3.5$ & $48.6 \pm 3.5$ & $54.2 \pm 4.2$ & $49.2 \pm 4.1$ \\
\hline Monocytes & $1.6 \pm 0.3$ & $3.5 \pm 0.3^{*}$ & $2.8 \pm 0.4^{*}$ & $3.1 \pm 0.4^{*}$ \\
\hline
\end{tabular}

Note: the difference between the indices in piglets with a diarrhoeal syndrome and clinically healthy piglets was significant at $*-\mathrm{P}<0.05, * *-\mathrm{P}<$ $0.01,{ }^{* * *} \mathrm{P}<0.001$.

Significant changes in the number of leukocytes in PEDv infected piglets on average 1.98 times $(\mathrm{P}<0.05)$ in comparison with control group of animals indicate the stimulation of cellular immunity. However, the detected leukocytosis in infected piglets was accompanied by a 1.96 times $(\mathrm{P}<0.05$ increase in the number of monocytes, which indicates the preferential development of subpopulations of phagocytes).

Thus, the PED virus induces an increase in the blood the count of erythrocytes and leukocytes, including monocytes, as well as the level of hemoglobin, hematocrit and ESR indicator.

The results of immunological studies of blood samples, which reflect the state of the nonspecific immune defense of the body of piglets infected with PEDv are presented in Table 2.

Table 2

Immunobiological status of the body of piglets $(x \pm S E)$

\begin{tabular}{|c|c|c|c|c|}
\hline $\begin{array}{l}\text { Indicators of the } \\
\text { immune status of } \\
\text { the microorganism }\end{array}$ & $\begin{array}{c}\text { Control } \\
\text { (clinically } \\
\text { healthy, intact } \\
\text { animals) } \\
(\mathrm{n}=6)\end{array}$ & $\begin{array}{l}\text { Piglets with } \\
\text { diarrhoeal } \\
\text { syndrome } \\
\text { from the farm } \\
\text { No } 1(\mathrm{n}=28)\end{array}$ & $\begin{array}{l}\text { Piglets with } \\
\text { diarrhoeal } \\
\text { syndrome } \\
\text { from the farm } \\
\text { No } 2(n=44)\end{array}$ & $\begin{array}{l}\text { Piglets with } \\
\text { diarrhoeal } \\
\text { syndrome } \\
\text { from the farm } \\
\text { No } 3(\mathrm{n}=32)\end{array}$ \\
\hline $\mathrm{IgG}, 1$ & $5.66 \pm 0.34$ & $5.42 \pm 0.24$ & $5.68 \pm 0.36$ & $5.62 \pm 0.38$ \\
\hline $\operatorname{IgM}$, & 0.48 & 0.72 & $.02 *$ & $0.06^{*}$ \\
\hline $\operatorname{IgA}, \mathrm{n}$ & 0.12 & & & 0.01 \\
\hline Lask, & $3.42=$ & & & \\
\hline Basque, $\%$ & 96.30 & 96.8 & & \\
\hline FAL, $\%$ & $71.48 \pm$ & 84.22 & 79.94 & 74.7 \\
\hline $\mathrm{FCH}, \mathrm{U}$ & $6.66 \pm$ & & & \\
\hline $\mathrm{FI}, \mathrm{U}$ & $7.67 \pm 0.34$ & $8.66 \pm 0.24$ & $8.86 \pm 0.44$ & $8.56 \pm 0.36$ \\
\hline
\end{tabular}

Note: the difference between the indices in piglets with a diarrhoeal syndrome and clinically healthy piglets was significant at $*-\mathrm{P}<0.05, * *-\mathrm{P}<$ $0.01, * * *-\mathrm{P}<0.001$.

The presented results of indicators of humoral immunity of piglets infected with the PED virus indicate activation of the initial stage of the development of the immune system. In the first place, this is evidenced 
by the increase of IgM concentration as a key indicator of the primary immune response, by $53.5 \%$ compared to the clinically healthy piglets of the group. The activation of phagocytic immunity is also noted, as evidenced by the increase in the relative number of activated phagocytes by $11.4 \%$, phagocytic number by $11.7 \%$ and phagocytic index by $13.3 \%$ compared to the control group of piglets.

There were no changes in such indicators as the concentration of $\operatorname{IgG}$ and $\operatorname{IgA}$, the level of bactericidal and blood serum lysozyme activity, which may be mediated immunosuppressive effects of PEDv. Thus, the PED infectious process in piglets induces an increase in the level of IgM in the peripheral blood and the number of phagocytic leukocytes with increased aggressiveness and digestive capacity.

The analysis of the biochemical parameters of blood of piglets indicates their depletion in piglets with PED diarrhea syndrome and the development of toxicosis on the background of dehydration (Table 3).

Table 3

Biochemical values of the piglets' blood $(\mathrm{x} \pm \mathrm{SE})$

\begin{tabular}{|c|c|c|c|c|}
\hline $\begin{array}{l}\text { Blood chemistry } \\
\text { value }\end{array}$ & $\begin{array}{c}\text { Control } \\
\text { (clinically } \\
\text { healthy, intact } \\
\text { animals) } \\
(\mathrm{n}=6)\end{array}$ & $\begin{array}{l}\text { Piglets with } \\
\text { diarrhoeal } \\
\text { syndrome } \\
\text { from the farm } \\
\text { No } 1(\mathrm{n}=28)\end{array}$ & $\begin{array}{l}\text { Piglets with } \\
\text { diarrhoeal } \\
\text { syndrome } \\
\text { from the farm } \\
\text { No } 2(n=44)\end{array}$ & $\begin{array}{l}\text { Piglets with } \\
\text { diarrhoeal } \\
\text { syndrome } \\
\text { from the farm } \\
\text { No } 3(\mathrm{n}=32)\end{array}$ \\
\hline Total protein, $\mathrm{g} / \mathrm{dm}^{3}$ & $58.46 \pm 3.60$ & $43.19 \pm 2.65^{*}$ & $47.46 \pm 2.18^{*}$ & $45.74 \pm 2.97 *$ \\
\hline Albumins, $\mathrm{g} / \mathrm{dm}^{3}$ & $\begin{array}{c}24.24 \pm \\
2.80\end{array}$ & $\begin{array}{l}10.97 \pm \\
1.56^{* *}\end{array}$ & $\begin{array}{c}14.03 \pm \\
2.07^{*}\end{array}$ & $\begin{array}{l}11.54 \pm \\
1.44 * *\end{array}$ \\
\hline Globulins, $\mathrm{g} / \mathrm{dm}^{3}$ & $34.22 \pm 3.14$ & $32.22 \pm 2.21$ & $33.43 \pm 3.15$ & $34.20 \pm 2.31$ \\
\hline$\alpha$-amylase, $\mathrm{E} / \mathrm{dm}^{3}$ & $\begin{array}{c}112.5 \pm \\
7.1\end{array}$ & $\begin{array}{l}198.4 \pm \\
12.4^{* *}\end{array}$ & & $\begin{array}{l}166.6 \pm \\
11.7^{* *}\end{array}$ \\
\hline AST, $\mathrm{U} / \mathrm{dm}^{3}$ & $44.28 \pm 2.61$ & $93.17 \pm 8.85^{*}$ & $102.64 \pm 10.22 *$ & $78.98 \pm 8.44^{*}$ \\
\hline ALT, $U / \mathrm{dm}^{3}$ & $40.77 \pm$ & $63.18 \pm$ & $71.15=$ & 64.28 \\
\hline AST/ALT ratio, $\mathrm{U}$ & $1.09 \pm$ & $1.47 \pm$ & 1.44 & 0.25 \\
\hline Crea & $84.98=$ & 102.50 & 97.10 & 88.70 \\
\hline Urea $\mathrm{mmol} / \mathrm{dm}^{3}$ & $2.66 \pm 0.20$ & $5.61 \pm$ & $4.98=$ & $5.13=$ \\
\hline $\begin{array}{l}\text { Cholesterol, } \\
\mathrm{mmol} / \mathrm{dm}^{3}\end{array}$ & $5.96 \pm 0.80$ & $1.84 \pm 0.64^{* *}$ & $2.11 \pm 0.95^{* *}$ & $0.75 \pm 0.12^{* *}$ \\
\hline $\begin{array}{l}\text { Alkaline phospha- } \\
\text { tase, } \mathrm{U} / \mathrm{dm}^{3}\end{array}$ & $138.7 \pm 18.1$ & $417.5 \pm 42.3^{*}$ & $352.3 \pm 32.7^{*}$ & $377.9 \pm 31.6^{*}$ \\
\hline Calcium, $\mathrm{mmol} / \mathrm{dm}^{3}$ & $2.53 \pm 0.12$ & $2.34 \pm 0.34$ & $2.81 \pm 0.42$ & $2.49 \pm 0.37$ \\
\hline $\begin{array}{l}\text { Inorganic phos- } \\
\text { phorrus, } \mathrm{mmol} / \mathrm{dm}^{3}\end{array}$ & $1.51 \pm 0.19$ & $1.46 \pm 0.12$ & $1.68 \pm 0.14$ & $1.39 \pm 0.12$ \\
\hline $\mathrm{Ca} / \mathrm{P}, \mathrm{U}$ & $1.75 \pm 0.19$ & $1.60 \pm 0.15$ & $1.67 \pm 0.12$ & $1.79 \pm 0.18$ \\
\hline $\begin{array}{l}\text { General lipopro- } \\
\text { teins, } \mathrm{mg} \%\end{array}$ & $185.9 \pm 15.8$ & $46.7 \pm 4.7^{* *}$ & $28.2 \pm 3.5^{* *}$ & $32.4 \pm 4.2 * *$ \\
\hline Glucose, $\mathrm{mmol} / \mathrm{dm}^{3}$ & $5.07 \pm 0.48$ & $1.85 \pm 0.32 *$ & $2.01 \pm 0.26^{*}$ & $1.64 \pm 0.44^{*}$ \\
\hline
\end{tabular}

Note: the difference between the indices in piglets with a diarrhoeal syndrome and clinically healthy piglets was significant at $*-\mathrm{P}<0.05, * *-\mathrm{P}<$ $0.01, * * * \mathrm{P}<0.001$.

The results of the biochemical analysis of blood showed a significant decrease in the total protein content in the blood serum of piglets with diarrhea syndrome on average by $22.2 \%(\mathrm{P}<0.05)$ due to a decrease by $49.8 \%$ of the albumin fraction $(\mathrm{P}<0.01-0.05)$, in comparison with clinically healthy piglets. Moreover, in sick animals, a violation of lipid and carbohydrate metabolism is indicated. Blood samples of infected piglets showed a decrease in cholesterol level by $73.7 \%(\mathrm{P}<0.01)$, glucose by $63.8 \%(\mathrm{P}<0.05)$ and total lipoproteins by $80.8 \%(\mathrm{P}<0.01)$ and an increase in the urea content of 1.97 times $(\mathrm{P}<0.01)$ in comparison with healthy piglets.

The results of biochemical analyses of enzyme activity in blood serum of piglets showed the increase of the activity of $\alpha$-amylase and alanine aminotransferase on the average by $72.4 \%(\mathrm{P}<0.01)$ and $62.4 \%(\mathrm{P}<$ $0.05)$, respectively, and alkaline phosphatase and aspartate aminotransferase by 2.76 times $(\mathrm{P}<0.05)$ and 2.07 times $(\mathrm{P}<0.05)$, respectively, in comparison with clinically healthy piglets.

The species composition of the intestinal microbiocenosis and the quantitative ratio of the main groups of microbionts determined no enteropathogenic species of Salmonella, Yersinia, Proteus, Enterococcus and Pseudomonas (Table 4). The exception to the common data was the identification of hemolytic E. coli, which were identified in six cases. The intestinal pathology in piglets, accompanied by hemolytic $E$. coli, did not differ from other clinical manifestations of watery diarrhea involving non- hemolytic $E$. coli in terms of the severity of diarrheal syndrome. The phenomenon of hemolysis of erythrocytes by $E$. coli on plain agar did not correlate with the severity of the pathogenesis of coronavirus diarrhea, and in a biological test on white mice there was no death in mice, which, however, does not disprove the potential likelihood of the presence of virulent properties, but does not confirm their presence as a result of clinical observations.

Table 4

Microbiocenosis of the piglets' intestines $\left(\mathrm{n} \times 10^{\mathrm{n}} \mathrm{CFU} / \mathrm{G} ; \mathrm{x} \pm \mathrm{SE}\right)$

\begin{tabular}{|c|c|c|c|c|}
\hline Microorganisms & $\begin{array}{c}\text { Control } \\
\text { (clinically } \\
\text { healthy, intact } \\
\text { animals) } \\
(\mathrm{n}=6)\end{array}$ & $\begin{array}{l}\text { Piglets with } \\
\text { diarrhoeal } \\
\text { syndrome } \\
\text { from the farm } \\
\text { No } 1(\mathrm{n}=28)\end{array}$ & $\begin{array}{l}\text { Piglets with } \\
\text { diarrhoeal } \\
\text { syndrome } \\
\text { from the farm } \\
\text { No } 2(n=44)\end{array}$ & $\begin{array}{l}\text { Piglets with } \\
\text { diarrhoeal } \\
\text { syndrome } \\
\text { from the farm } \\
\text { No } 3(\mathrm{n}=32)\end{array}$ \\
\hline MAFAM & $\begin{array}{c}4.8 \times 10^{6} \pm \\
3.2 \times 10^{5}\end{array}$ & $\begin{array}{c}6.2 \times 10^{7} \pm \\
5.6 \times 10^{6}\end{array}$ & $\begin{array}{c}4.8 \times 10^{8} \pm \\
3.4 \times 10^{7}\end{array}$ & $\begin{array}{c}7.9 \times 10^{7} \pm \\
6.2 \times 10^{6}\end{array}$ \\
\hline $\begin{array}{l}\text { Nonhaemolytic } \\
\text { E. coli }\end{array}$ & $\begin{array}{l}3.6 \times 10^{8} \pm \\
2.9 \times 10^{7}\end{array}$ & $\begin{array}{c}4.4 \times 10^{9} \pm \\
3.7 \times 10^{8}\end{array}$ & $\begin{array}{c}6.1 \times 10^{9} \pm \\
4.6 \times 10^{8}\end{array}$ & $\begin{array}{c}8.7 \times 10^{8} \pm \\
6.8 \times 10^{7}\end{array}$ \\
\hline $\begin{array}{l}\text { Haemolytic } \\
\text { E. coli }\end{array}$ & 0 & $\begin{array}{l}6.2 \times 10^{7} \pm \\
4.9 \times 10^{6 x}\end{array}$ & 0 & 0 \\
\hline Enterococcus spp. & $\begin{array}{c}4.4 \times 10^{6} \pm \\
2.3 \times 10^{5}\end{array}$ & $\begin{array}{c}5.3 \times 10^{7} \pm \\
3.3 \times 10^{6}\end{array}$ & $\begin{array}{c}6.7 \times 10^{8} \pm \\
4.1 \times 10^{7}\end{array}$ & $\begin{array}{c}8.2 \times 10^{7} \pm \\
6.2 \times 10^{6}\end{array}$ \\
\hline Proteus spp. & $\begin{array}{c}3.2 \times 10^{4} \pm \\
2.2 \times 10^{3}\end{array}$ & $\begin{array}{c}2.7 \times 10^{6} \pm \\
1.1 \times 10^{5}\end{array}$ & $\begin{array}{c}5.8 \times 10^{5} \pm \\
3.3 \times 10^{4}\end{array}$ & $\begin{array}{c}6.6 \times 10^{5} \pm \\
3.2 \times 10^{4}\end{array}$ \\
\hline Pseudomonas spp. & $\begin{array}{c}6.3 \times 10^{3} \pm \\
2.8 \times 10^{2}\end{array}$ & $\begin{array}{c}3.3 \times 10^{3} \pm \\
1.4 \times 10^{2}\end{array}$ & $\begin{array}{c}4.8 \times 10^{3} \pm \\
2.3 \times 10^{2}\end{array}$ & $\begin{array}{c}5.6 \times 10^{3} \pm \\
2.4 \times 10^{2}\end{array}$ \\
\hline Clostridium spp. & $\begin{array}{c}5.6 \times 10^{3} \pm \\
4.1 \times 10^{2}\end{array}$ & $\begin{array}{c}8.7 \times 10^{4} \pm \\
8.4 \times 10^{2}\end{array}$ & $\begin{array}{c}8.5 \times 10^{5} \pm \\
7.7 \times 10^{2}\end{array}$ & $\begin{array}{c}6.4 \times 10^{6} \pm \\
2.9 \times 10^{2}\end{array}$ \\
\hline Anthracoids & $\begin{array}{c}6.6 \times 10^{3} \pm \\
3.2 \times 10^{2}\end{array}$ & $\begin{array}{l}7.6 \times 10^{4} \pm \\
3.6 \times 10^{3}\end{array}$ & $\begin{array}{c}6.8 \times 10^{5} \pm \\
3.1 \times 10^{4}\end{array}$ & $\begin{array}{l}8.3 \times 10^{6} \pm \\
2.6 \times 10^{5}\end{array}$ \\
\hline Yeast-like fungi & $\begin{array}{c}6.1 \times 10^{3} \pm \\
2.6 \times 10^{2}\end{array}$ & $\begin{array}{c}6.5 \times 10^{5} \pm \\
4.1 \times 10^{4}\end{array}$ & $\begin{array}{c}2.4 \times 10^{5} \pm \\
1.2 \times 10^{4}\end{array}$ & $\begin{array}{c}2.2 \times 10^{6} \pm \\
1.2 \times 10^{5}\end{array}$ \\
\hline $\begin{array}{l}\text { Lactobacterium } \\
\text { spp. }\end{array}$ & $\begin{array}{c}4.5 \times 10^{7} \pm \\
2.2 \times 10^{6}\end{array}$ & $\begin{array}{c}4.3 \times 10^{3} \pm \\
2.1 \times 10^{2}\end{array}$ & $\begin{array}{c}6.8 \times 10^{3} \pm \\
2.4 \times 10^{2}\end{array}$ & $\begin{array}{c}6.3 \times 10^{3} \pm \\
2.5 \times 10^{2}\end{array}$ \\
\hline $\begin{array}{l}\text { Bifidobacterium } \\
\text { spp. }\end{array}$ & $\begin{array}{c}4.6 \times 10^{5} \pm \\
2.3 \times 10^{4}\end{array}$ & $\begin{array}{c}5.2 \times 10^{3} \pm \\
2.1 \times 10^{2}\end{array}$ & $\begin{array}{c}2.3 \times 10^{4} \pm \\
1.8 \times 10^{3}\end{array}$ & $\begin{array}{c}7.4 \times 10^{3} \pm \\
3.3 \times 10^{2}\end{array}$ \\
\hline $\begin{array}{l}\text { Aerococcus } \\
\text { viridans }\end{array}$ & $\begin{array}{c}8.4 \times 10^{3} \pm \\
3.4 \times 10^{2}\end{array}$ & 0 & $1.0 \times 10$ & 5.0 \\
\hline
\end{tabular}

Note: ${ }^{\times}-\mathrm{n}=6$.

All types of microorganisms identified in the internal contents of the intestine in biological samples on laboratory animals were apathogenic and had a pronounced biochemical activity with respect to nitrogen and carbon-containing compounds, that is, they were ubiquitous saprophytes ammonificators and pathogens of fermentation processes.

Noteworthy is the complete absence of Aerococcus viridans in the intestinal contents of the sick piglets.

The biological study of the pathogen to confirm the specificity of the etiological factor of the diarrheal syndrome was conducted on a sensitive biological model represented by non-immune neonatal piglets when PED infected. For making the bioassay in the PED-free reproducer, 6 clinically 1-2 day old healthy piglets were selected and orally infected with crushed biomaterial (intestine) of dead animals with the PED symptom complex. The infectious dose was $50 \times 10^{6}$ of PEDv equivalent equivalents per piglet upon oral introduction of the pathogen.

The results of clinical observation indicate that the incubation period lasted 8 to 12 hours, after which watery diarrhea began. Defecation was frequent, feces liquefied to a watery state, were yellowish or colourless, and diarrhea was often accompanied by severe vomiting. The intensity of the severity of pathogenesis steadily increased over time. The diarrhea observed in the study quickly lead to dehydration. Against the background of complete abandonment of interest in food, dehydration and increasing intoxication, the animals lost their live weight, their emaciation at the terminal stage of the infectious process turned into pathologically marked exhaustion. Diarrheal syndrome lasted from two to four days, during which all infected piglets died.

\section{Discussion}

The results of the study showed that the death of piglets in the first postnatal days was widespread. Mortality reached $100 \%$, and the dura- 
tion of pathogenesis amounted to 3-4 days. In the feces of piglets with clinical manifestations of diarrhea syndrome, PEDv RNA was identified using RT-PCR. The retrospective epidemiological study previously found that infectious disease occurred from replacement gilts in the form of mild diarrheal syndrome with a small coverage of the population. Further, in the study of serum of convalescent animals by ELISA, specific antibodies to PEDv antigens in diagnostic titer $1: 10$ were detected in $38 \%$ of animals.

The similarity of both clinical and epidemiological development of PEDv infection corresponds to two typical outcomes that occur either by the classical type with a fatal diarrheal syndrome in neonatal nonimmune piglets, or the type of non-lethal diarrheal syndrome, with a relatively mild course in animals of older age groups. Therefore, the only effective way to prevent the onset and development of incurable lethal diarrhea syndrome in neonatal non-immune piglets is preventive protection of lactogenic origin from the first hours of life. Similar recommendations have been proposed by many researchers (Stevenson et al., 2013; Stadler et al., 2015).

In addition, the infection of the non-colostrum piglets from the farms with the PEDv was carried out in order to identify the main characteristics of the infection progress and the development of the immune response. Oral infection of newborn piglets with a vaccinated dose of $5 \times 10^{7}$ of genome-equivalents of the pathogen led to the death of all experimental piglets. A hyperacute course of infection was detected in all individuals of this group. Moreover, the clinical results showed the presence of the classic severe type of pathogenesis and the absolute mortality of infected animals. The results obtained allow us to consider the dose of the virus used for the infection as an emergent, leading to undoubted death - dosis certa letalis (DCL).

Given that the infecting dose of PEDv in an amount of $5 \times 10^{7}$ of genome equivalents administered to newborn piglets in our experiment was estimated as lethal (DCL), this dose can be taken as a critical value of infecting dose of the strain. The obtained result showed that $5 \times 10^{7}$ of PEDv genome equivalents can be used for direct control infection in testing the immunological potency of prophylactic biologic drugs, as it leads to $100 \%$ their death of the infected animals as a result of pathophysiological disorders, which are incompatible with life, induced by reproduction of PEDv in intestinal enterocytes. The acute infection in our study is confirmed by the results of the path analysis which revealed pathognomic changes peculiar to the PED virus, as well as the PEDvpositive result of PCR analysis in the small intestine tissues of infected piglets. Pillatzki et al., (2015) demonstrated an important feature of the dynamics of PED infection. They revealed that an increase in infecting dose of PEDv reduces the duration of the incubation period of the disease for the time necessary for the initial stage of the virus reproduction in the enterocytes to the first generation of the pathogen. Further, there is a massive infection of the epithelium of the small intestine, with the result that the infectious process is accompanied by the development of watery diarrhea syndrome, as indicated in the results of Stevenson et al. (2013), Stadler et al. (2015), Boonsoongnern et al. (2015).

The features of PEDv pathogenesis in the model of germ-free piglets that did not receive colostrum are presented in the work of Jung et al. (2014). Three day old neonatal piglets were inoculated with a prototype strain PC21A. The first disease symptoms in the group of infected animals were detected after 22-36 hours, which coincides with the results obtained in our monitoring experiment of infectious pathology in pig-breeding farms. Localization and intensive reproduction of the PEDv in the small intestine of piglets was demonstrated using fluorescent probes in the study by Jung et al. (2015).

The results obtained in our study showed that on the farms of Ukraine the PEDv almost completely ceased to be excreted with the feces of convalescents $37 \pm 2$ days after cessation of the diarrhea syndrome. Infection of intestinal epithelial cells occurs in the first 1218 hours after inoculation of the virus and reaches a maximum in 24 36 hours, which is confirmed by the results of RT-PCR. On the 37th day after infection, the detected virus concentration was estimated to range from $12 \pm 6$ to $1700 \pm 80$ of genome equivalents in $1 \mathrm{~g}$ of the biomaterial. Multiplication of the pathogen outside the cells of the intestine does not happen, which is very important in the study of the mecha- nisms and duration of virus shedding in convalescent piglets. The data obtained in our experiment are consistent with the results of other studies on the timing of conditional and clinical recovery of piglets after initial PED infection (Pasick et al., 2014; Mesquita et al., 2015; Pizzurro et al., 2018).

The results of the post-mortem observation revealed signs of deep exhaustion, in particular, anemia of the skin and mucous membranes. The results of biochemical blood tests in piglets with clinical manifestations of the PED virus showed a violation of the content of hepatospecific enzymes: aspartate- and alanine aminotransferase. The data obtained confirm the fact that the animals died as a result of alimentary dystrophy and severe autointoxication in combination with the phenomena of metabolic acidosis. Moreover, a decrease in the level of cholesterol, glucose and total lipoproteins was detected in the blood samples of infected piglets, which indicates the depletion of the energy reserves of their body. The increased activity of $\alpha$-amylase and alkaline phosphatase was also shown, which may be due to inflammation of the small intestine, induced by the PED virus. Thus, the results of biochemical studies of blood serum of piglets with clinical manifestations of the PED virus indicate intoxication of the body, as indicated by elevation of transaminases and on the background of dehydration and exhaustion.

The results of the hematological analysis of the blood of piglets with diarrheal syndrome induced by the PEDv indicate a hemoconcentration, which is accompanied by an increase in the number of formed elements and the hematocrit index. Hemoconcentration is an extremely unfavourable pathophysiological phenomenon, as it leads to oxygen deficiency of tissues, especially the brain, as a vital center. An increase in the ESR indicator was also found, which depends on the degree of aggregation of erythrocytes and plasma concentration of "acute phase proteins" - markers of the inflammatory process.

The numerical increase in immune competent cells that possess phagocytic ability indicates the development of the initial stage of the inflammatory process with involvement in the process of immunogenesis and the formation of the primary immune response. It is crucial that the primary cell-mediated mechanism is provided with an increase in the specificity of the antigen-binding centers of antibodies to antigen determinants of the virus. As a result of the growth of the antibody affinity, the formation of a directed PEDv specific immunity in the body of piglets occurs.

The increase in the level of IgM and the activity of phagocytic leukocytes detected in our experiment also indicates the initiation of the primary humoral response to PEDv infection. IgM antibodies are the key factor in the development of the primary immune response, since they are most effective in recognizing antigens of various types (Joling et al., 1993; Tizard, 2009). Moreover, IgM have a higher ability to activate the complementary system, which acts as a powerful tool to eliminate particulate antigens, including viruses (Roos et al., 2008). It is worth noting here that the formation of local immunity in the mucous membranes of the small intestine, where the effects of PEDv are mainly focused, requires the activation of macrophage and neutrophil effector cells (Yuan et al., 2018). The increase in the phagocytic activity of small forms of phagocytic cells that we detected may be the result of the development of the body's immune response in the monitored period of 16-18th days of the piglets' life. No significant differences in the content of IgG, IgA, as well as in the bactericidal and lysozyme activity of all of them were found in the blood of piglets. This fact can be explained by the fact that the extremely rapid development of the PED infectious process in newborn piglets leads to a lethal outcome (Jung et al., 2014). Unfortunately, a short period of infection of about 3-5 days is the main cause, which can explain why it is impossible to generate and to multiply to a sufficient number specific clones of lymphocytes, which produce enough IgG and IgA to detect changes.

Thus, molecular and cell-mediated immunological events indicate the initial stage of development of a specific immune response to PEDv.

The results of the histological examination of the small intestine of piglets infected with the PED virus indicate thinning of its wall due to shortening of the villi. The revealed ratio of the length of the villi and the depth of the crypts of $3: 1$ was significantly less than the normal physiological ratio of $7: 1$. Such a morphological disturbance, in the 
first place, may be due to the intense replication of the virus and the total death of enterocytes (Boonsoongnern et al., 2018). The results presented in our study have shown the absence of microbial species that have a specific pathogenic effect. The composition of the gastrointestinal microbiota with watery diarrhea of piglets is also poorly understood and insufficiently covered in the scientific literature. The role of intestinal microflora in the PED infectious process in newborn piglets remains unexplored (Ma et al., 2018). The results of microbiological analysis showed that the species composition and quantitative ratio of microbiota in the intestine of piglets correspond to microbiota of the environment. The species (taxonomic) composition of microorganisms is normergic and does not include specific prokaryotic pathogens. The microflora identified in the small intestine of piglets is saprophytic, enzymatically active. It is important to note the decrease in the share of probiotic microorganisms, among which Aerococcus viridans, which is an indicator of the clinical well-being of animals, is completely absent. It is a known fact that this is a resident representative of the open cavities of healthy animals and an indicator of the normergic composition of the microbiocenosis in a state of clinical well-being, and its absence is a prognostically unfavourable symptom in relation to the health and life of the organism. Synergistically with aerococci, the content of lacto- and bifidobacteria is sharply reduced, which also indicates the clinical distress of the examined piglets. Thus, the relatively short period between PEDv infection and death can be the main reason for the absence of changes in the composition of the microflora.

\section{Conclusions}

The PED virus induces super-acute pathogenesis in 1-7 day old non-immune piglets. PED infection accords to the classic type and accompanied with a relay transmission of the pathogen, the development of irreversible and life-incompatible pathophysiological lesions, which are caused by PEDv replication in enterocytes of piglets. Pathogenetic disturbances determined in PEDv infected piglets include the acute inflammatory-necrotic process, destruction and desquamation of the epithelium of the small intestine. The infection process is accompanied by an increase in the erythrocyte count, phagocytic activity of leukocytes and monocytes, aminotransferase activity, as well as an increment of IgM content at 3-5 days of manifestation of clinical signs of the PED virus. The release of the PED virus with feces takes place 26 37 days after cessation of watery diarrhea. The concentration of PEDv in the feces of convalescent piglets ranged from $12 \pm 6$ to $1700 \pm 80$ of genome equivalents in $1 \mathrm{~g}$ of tissue. Parasite coenotic associations in the microbiocenosis of the digestive tract of PEDv infected piglets were not have observed. The intestinal microflora consists of random transient microbiota of the environment with pathogenic properties.

\section{References}

Boonsoongnern, P., Boonsoongnern, A., Pongchairerk, U., \& Paompa, T. (2018). The comparison of villous damage at different ages of piglets infected with porcine epidemic diarthea virus. Chiang Mai Veterinary Journal, 16(1), 37-46.

Chen, Q., Gauger, P. C., Stafne, M. R., Thomas, J. T., Madson, D. M., Huang, H., Zheng, Y., Li, G., \& Zhang, J. (2016). Pathogenesis comparison between the United States porcine epidemic diarrhoea virus prototype and S-INDELvariant strains in conventional neonatal piglets. Journal of General Virology, $97,1107-1121$.

Crawford, K., Lager, K., Miller, L., Opriessnig, T., Gerber, P., \& Hesse, R. (2015). Evaluation of porcine epidemic diarrhea virus transmission and the immune response in growing pigs. Veterinary Research, 46-49.

Hu, H., Jung, K., Vlasova, A. N., Chepngeno, J., Lu, Z., Wang, Q., \& Saif, L. J. (2015). Isolation and characterization of porcine deltacoronavirus from pigs with diarrhea in the United States. Journal of Clinical Microbiology, 53, $1537-1548$.

Joling, P., Mok, K. S., Reilingh, G. V., \& Wever, P. J. (1993). An evaluation of immune competence in different swine breed. The Veterinary Quarterly, $15(1), 9-15$.
Jung, K., Eyerly, B., Annamalai, T., Lu, Z., \& Saif, L. J. (2015). Structural alteration of tight and adherens junctions in villous and crypt epithelium of the small and large intestine of conventional nursing piglets infected with porcine epidemic diarrhea virus. Veterinary Microbiology, 177, 373-378.

Jung, K., Wang, Q., Scheuer, K. A., Lu, Z., Zhang, Y., \& Saif, L. J. (2014). Pathology of US porcine epidemic diarrhea virus strain PC21A in gnotobiotic pigs. Emerging Infectious Diseases journal, 20, 662-665.

Kocherhans, R., Bridgen, A., Ackermann, M., \& Tobler, K. (2001). Completion of the porcine epidemic diarrhoea coronavirus (PEDV) genome sequence. Virus Genes, 23, 137-144.

Lee, C. (2015). Porcine epidemic diarrhea virus: An emerging and re-emerging epizootic swine virus. Virology Journal, 12, 193.

Lin, C. M., Gao, X., Oka, T., Vlasova, A. N., Esseili, M. A., Wang, Q., \& Saif, L. J. (2015). Antigenic relationships among porcine epidemic diarrhea virus and transmissible gastroenteritis virus strains. Journal of Virology, 89, 3332-3342.

Lowe, J., Gauger, P., Harmon, K., Zhang, J., Connor, J., Yeske, P., Loula, T., Levis, I., Dufresne, L., \& Main, R. (2014). Role of transportation in spread of porcine epidemic diarrhea virus infection, United States. Emerging Infectious Diseases Journal, 20(5), 872-874.

Ma, S., Wang, L., \& Huang, X. (2018). Oral recombinant Lactobacillus vaccine targeting the intestinal microfold cells and dendritic cells for delivering the core neutralizing epitope of porcine epidemic diarrhea virus. Microbial Cell Factories, 17, 1-12.

Masiuk, D. N., Nedzvetsky, V. S., Sosnitskiy, A. I., Kokarev, A. V., \& Koliada, S. G. (2018). The characteristics, emergent properties and manner of spread in Ukraine of the Porcine Epidemic Diarrhea Virus. Regulatory Mechanisms in Biosystems, 9(3), 401-408.

Mesquita, J. R., Honing, H., Almeida, R., Lourenço, A., Poel, M., \& Nascimento, M. S. (2015). Outbreak of porcine epidemic diarrhea virus in Portugal. Transboundary and Emerging Diseases, 62, 586-588.

Miller, L. C., Crawford, K. K., Lager, K. M., Kellner, S. G., \& Brockmeier, S. L. (2016). Evaluation of two real-time polymerase chain reaction assays for Porcine epidemic diarrhea virus (PEDV) to assess PEDV transmission in growing pigs. Journal of Veterinary Diagnostic Investigation, 28, 20-29.

Pasick, J., Berhane, Y., Ojkic, D., Maxie, G., Embury-Hyatt, C., Swekla, K., Handel, K., Fairles, J., \& Alexandersen, S. (2014). Investigation into the role of potentially contaminated feed as a source of the first-detected outbreaks of porcine epidemic diarrhea in Canada. Transboundary and Emerging Diseases, 61, 397-410.

Pillatzki, A., Gauger, P., Madson, D., Burrough, E., Zhang, J., Chen, Q., Magstadt, D., Arruda, P., Stevenson, G., \& Yoon, K. J. (2015). Experimental inoculation of neonatal piglets with feed naturally contaminated with porcine epidemic diarrhea virus (PEDV). Journal of Swine Health and Production, 23 (6), 317-320.

Pizzurro, F., Cito, F., Zaccaria, G., Spedicato, M., Cerella, A., Orsini, M., Forzan, M., D'Alterio, N., Lorusso, A., \& Marcacci, M. (2018). Outbreak of porcine epidemic diarrhoea virus (PEDV) in Abruzzi region, Central Italy. Veterinary Medicine and Science, 4, 73-79.

Roos, A., Essers, M., Van Gijlswijk-Janssen, D., Bovin, N. V., \& Daha, M. R. (2008). Both IgG and IgM anti-pig antibodies induce complement activation and cytotoxicity. Xenotransplantation, 8, 3-14.

Stadler, J., Zoels, S., Fux, R., Hanke, D., Pohlmann, A., Blome, S., Weissenböck, H., Weissenbacher-Lang, C., Ritzmann, M., \& Ladinig, A. (2015). Emergence of porcine epidemic diarrhea virus in Southern Germany. BMC Veterinary Research, 11, 142.

Stevenson, G. W., Hoang, H., Schwartz, K. J., Burrough, E. R., Sun, D., Madson, D., Cooper, V. L., Pillatzki, A., Gauger, P., Schmitt, B. J., Koster, L. G., Killian, M. L., \& Yoon, K. J. (2013). Emergence of Porcine epidemic diarrhea virus in the United States: Clinical signs, lesions, and viral genomic sequences. Journal of Veterinary Diagnostic Investigation, 25, 649-654.

Thomas, J. T., Chen, Q., Gauger, P. C., Gimenez-Lirola, L. G., Sinha, A., Harmon, K. M., Madson, D. M., Burrough, E. R., Magstadt, D. R., Salzbrenner, H. M., Welch, M. W., Yoon, K. J., Zimmerman, J. J., \& Zhang, J. (2015). Effect of Porcine epidemic diarrhea virus infectious doses on infection outcomes in naive conventional neonatal and weaned pigs. PLoS One, 10, e0139266.

Tizard, I. R. (2009). Veterinary immunology: An introduction (6th edition). Saunders, Philadelphia.

Yuan, P., Yang, Z., Yang, Y., Wang, K., Dong, W., Song, H., Wang, L., \& Song, Z. H. (2018). Structural and non-structural proteins of porcine epidemic diarrhea virus against congenital immunity of host cells. Journal of Gastroenterology, Hepatology and Endoscopy, 3(2), 1-6. 